\title{
Identification and estimation of the marine ecosystem services surrounding selected offshore islands of Vietnam
}

\section{Autores}

Tran Dinh Lan, Nguyen Thi Minh Huyen, Hoang Thi Chien, Luc Hens

\begin{abstract}
Intertidal and larger marine ecosystems surrounding the islands of Bach Long Vi (Northern Vietnam), Con Co (Central Vietnam) and Tho Chu (Southernmost Vietnam) which have typical and valuable ecosystems are planned as marine protected areas. They are the study area of this paper on identification and estimation of these ecosystem services. The total economic valuation concept is used to estimate the total value of the ecosystems during the period March 2014 to October 2015. The marine ecosystems surrounding Bach Long Vi Island were estimated servicing 599,047.8 million VND (Vietnam Dong)/year in total (corresponding to 26.62 million USD (US dollar-1 USD = 22,503.68 VND (rate May 1, 2015)); calculated per hectare; this value corresponds with 94 million VND/year. The marine ecosystems surrounding Con Co Island provide a total monetary service of 267,518 million VND/year (approximately, 12 million USD/year); this corresponds with 307 million VND/ha/year. The marine ecosystems surrounding the Tho Chu archipelago were worth 565,236 million VND/year (approximately, 25 million USD/year); this corresponded with 125.47 million VND/ha/year. These figures show the most significant service value of marine ecosystems, particularly around the three islands.
\end{abstract}

Palabras clave

Marine ecosystem service, Island, Coral reef, Tidal wetland, Tropical region. 